\title{
Singing Satellites and Sounding Birds
}

Jakob Lien

History changed on October 4th 1957 when the Soviet Union successfully launched Sputnik 1, the world's first artificial satellite, and sent the first man-made object in orbit around Earth. Only one month later the Russians launched a second satellite, this time with a living passenger onboard - the famous space dog Laika. When the satellite reentered into earth's atmosphere 162 days later, Laika had already been dead for a long time. The following year, the Russian cosmonaut Yuri Gagarin, became the first human to journey into outer space and NASA was founded. The accelerating space race between the Soviet Union and the US was a fact and became a crucial component of the cold war era.

While the launch of the first satellites became a decisive factor in the frightening arms race, it was also a source of deep fascination for people all over the globe. Ten years after the launch, the Canadian media theorist Marshall McLuhan pointed out that the new satellite technology came to forever change our view of ourselves: "Our psyches acquire thereby a totally new 
rim-spin". With the help of the satellite, seeing ourselves from a wholly new perspective became possible for the first time. While the new space technologies celebrated great triumphs and space became the new frontier, satellite images at the same time accentuated the insignificance of humans on earth from a geomedial perspective. With the satellite as a vector for our fantasies, a kind of cosmic vertigo, or an ontological doubt, emerged. The notion that the human was an unchallenged focal point was suddenly disturbed. Both nature and technology appeared at this point more hostile and more fragile than ever before.

In 1987 the term "overview effect" was coined by the American author Frank White to describe the cognitive shift in awareness reported by astronauts during spaceflight, while looking at earth from orbit. ${ }^{1}$ Many returning space travelers have claimed that when viewing earth from such a distance, they were overwhelmed and awed by the fragility and unity of life. One astronaut said that he "was hit in the gut with an undeniable, sobering contradiction." It is this shift in our cultural imagination as it is examined by two Swedish art works from the 1960 s, that I want to focus on in this article.

\section{Birds in Sweden}

In early winter 1963, the artist Öyvind Fahlström's eclectic radio composition Birds in Sweden was broadcasted by the Swedish National Radio for the first time. The listeners that were awake in front of their radios that winter night would soon experience something they had never heard before. The 30-minute composition starts with the sound of steps on a staircase and a door shutting. After that, a voice is heard reading an allusive quote from a book about parapsychology before the soundtrack from the sci-fi movie The Forbidden Planet from 1956 is slowly cued in in the background. The composition, or the "radio-phonic poem" as Fahlström called it, then continues as a collage of sounds and voices in a strange mix of poetry readings, animal sounds, field recordings, speeches, music and noises from diffe-

1 The concept was coined and explored in his book The Overview Effect - Space Exploration and Human Evolution (1987). 
rent technologies (like jet engines and guns, for instance). And then, there is something else, something intermediate that oscillates between animate sounds, spoken language and complete nonsense. What the listener is hearing pop up from time to time throughout the radio composition is a language invented by Fahlström himself, called "fåglo" or, in its English version, "birdo". The title of the work, Birds in Sweden, gives us a clue as to what kind of languages these are. It is a direct loan from the title of the classic field guide to birds by the ornithologist Erik Rosenberg that came out 1953. This was thee first Swedish handbook containing onomatopoetic transcriptions of bird songs, something that triggered Fahlström to begin working on the radio composition. As Jesper Olsson has noted in an essay on Fahlström's sound art noted: "birds and their communication system were the catalyst for his work [Birds in Sweden]."

Why would Fahlströhm make up invented bird languages, one might ask? If we look at Fahlström's earlier aesthetic practices we find a continuity in his interest for communication systems and questions about the limits of language. 1953, 10 years before Birds in Sweden, Fahlström wrote the influential manifesto for concrete poetry where he describes the idea about "kneading language as concrete material". ${ }^{2}$ This endeavor to explore and systemize language, in order to be able to play with and manipulate it, is manifest also in his work with the invented languages birdo and fagglo - even though he now extends his antennas outside the purely human communicating system. Two early sketches from 1962 shows how Fahlström worked out these "artificial" languages as an act of translation where the syllables of a given word were mimicked with onomatopoetic counterparts. Birdo and fagglo are in fact translations from sound imitation to sound imitation through written language. The languages were not meant to be fully thought-out systems possessing inner logic and grammar, but are rather created as acts of "kneading" and exploring the limits of different sign, sound and communication systems. Or as Fahlström said in a radio interview in 1963: "I think the actual translation process is highly significant, as what

2 Öyvind Fahlström, "Hätila ragulpr på fåtskliaben”, Odyssé nr. 3-4, 1954. 
we are engaged in our [sic!] attempts at perceiving the world, in the way we perceive reality, is translation in accordance with various systems; all systems are of equal worth. [...] Language, too, is a meaningless system that is great fun to play with." ${ }_{3}$

If birds and their communication systems are the most obvious catalyst for Fahlström's work, there is another, maybe more elusive, but equally important catalyst for the radio composition as a whole - namely wireless communication systems. Radio is of course the most apparent technology at play here, but at the end of Birds in Sweden another technology is introduced. Over a cacophonic sound of birds, the music of the 1962 number one billboard hit by the surf group The Tornados slowly fade-in as a second layer in the soundscape. (fig. 5) The track is titled "Telstar", after the first private communication satellite launched less than one year before Birds in Sweden was broadcasted for the first time.

In an educational documentary about the Telstar satellite from the same year it was launched, we initially hear an alarming sound from a receiver turning its antenna up into the sky, poised to follow Telstar's orbit in space. After that, a film sequence of space is shown while dramatic music is played in the background, shortly thereafter the setting changes again. We are now back on earth and a calm voice can be heard, telling us about a "tiny spinning globe that will rise from the Florida beach." Whether or not Fahlström himself, who lived long periods of his life in America, saw this particular documentary, is impossible to determine, but it's not hard to envision what kind of fantasies such an event would spark in anyone's imagination. The success of The Tornados' odd sci-fi inspired surf song could hardly have been imaginable without a general excitement about this new technology. And considering Fahlström's interest in language as well as in communication and technology, it is almost a logic consequence that he found and incorporated the launch of the first private communication satellite as a crucial component of Birds in Sweden.

\footnotetext{
3 Fahlström talks about his work on Swedish National Radio in 1963. Teddy Hultberg, Öyvind Fahlström on the air - Manipulating the World: Birds in Sweden, The Holy Torsten Nilsson, Pictures \& Manuscripts, Sveriges Radio, Stockholm, 1999, p. 93.
} 
In many ways, the new communication satellite embodies the "perfect arc", to paraphrase McLuhan, between the animate sounds of birdsongs and the inanimate sounds of technologies. In cultural representations, birds have for a long time played the role of messengers, the connections between distant places - much like the satellite does today. A very concrete example is of course the carrier pigeon, but even in nature, birds function as agents of seed dissemination. The American art historian Sergio Bessa has noted that: "there are hints in Birds in Sweden of birds becoming machines, of machines as extensions of natural organisms, and ultimately of nature being superseded by technology." 4 I agree with Bessa to some extent, but would not go quite as far. Instead, I would suggest that there is a constant reciprocation between birds and technology, opening up for the possibility of satellites becoming birds as well.

The final lines in Birds in Sweden (that are interpretable for us humans) go: "kiss the earth, kiss the earth" and then "don't kiss the earth, don't kiss the earth". Isolated these words may "seem to apply a call to a return to nature", as Bessa suggests. ${ }^{5}$ But if we consider the larger context where these words can be heard, enmeshed in the sounds of jet engines, satellites, birdsong etc., the lines seem to suggest a transgression of traditional boundaries between nature, human, and technology. Creating a new ecology, highlighting a communication situation where human language is no longer the dominant form.

\section{Altisonans}

My second example exploring the shift in our cultural imagination in regard to technology and nature, is a film called Altisonans from 1966 by the Swedish artist and composer KarlBirger Blomdahl. The work was broadcasted as a part of an experimental film program on the national Swedish television, and it has a lot in common with Fahlström's work Birds in Sweden; both being broadcasted with wireless technologies but

\footnotetext{
4 Antonio Sergio Bessa, Övind Fahlström: The Art of Writing, Northwestern Univesity Press, Evanston, Ill., p. 127.

5 Ibid., p. 130.
} 
more importantly, both using birds and satellites as their main incentives to explore different communication systems. At the time Altisonans was finished, Blomdahl was a well-known composer and public figure in Sweden. Blomdahl became famous, not least, for introducing electronic music in an opera for the first time in Sweden, when his opera Aniara premiered in Stockholm in 1959. The opera is based on the Swedish Nobel prize winner Harry Martinson's sci-fi inspired 1956 poem of the same name. It became a huge success and is still today the most seen opera in Sweden. Blomdahl's interest in techno$\log y$ and nature goes back to the 1950 s when he started to do field recordings of earth sounds, which he then transposed into electronic music. Parts of these compositions were later used in Aniara. But it was when he met the Polish geo-cosmo-physician Ludwik Liszak for the first time, at a solar observatory at Capri, that the idea for Altisonans started to grow. When Liszak let Blomdahl listen to sounds from space, he realized that there were a lot of sonar similarities to birdsong - and more specifically to the mating call by the Naumann's Trush (or Rödtrast). He started to collaborate with Liszka and went to the geophysical observatory in Kiruna, located above the arctic circle, to do recordings of electromagnetic signals from satellites and astrophysical objects. The result can be described as an audio-visual collage of birdsongs that gradually coalesce with the sound of the man-made satellites in space. The work stages two parallel soundscapes - one "natural-sounding" world inhabited by birds on the face of the earth, and one artificial some hundred kilometers out in space - merge into a new kind of communication system. In communication theory voices and sounds usually are used to locate subjects and objects in the world, and by doing so, they are in a way restricted from the opportunity to explore and form new configurations. But in Blomdahl's work the sounds from the subjects and objects are instead used to breach borders between different entities and intertwine the parts they play in the ambient ecology formed by the new satellite technology.

So far, I have been focusing on these two works as historical 
examples of how the new satellite technology inspired artistic examinations and reconfigurations of aesthetic practices during the 1960 s. But I also think that both Birds in Sweden and Altisonans have a critical relevance today, not least in relation to the ongoing discussion about what has been called "the non-human turn" in humanities. Both works actualize the question of how we could tackle today's geo-political and social challenges as well as climate change, suggesting alternative ways of distributing our relations, not only to each other but also to the nonhuman beings around us.

Of course, talking about a non-human turn when satellites in fact are man-made technologies may seem murky, but rather than addressing these technologies as "extraordinary achievements by mankind" both Fahlström's and Blomdahl's works seem to focus on what happens after or beside human intervention. Erin Manning, an American artist and philosopher, have suggested that art always has a participatory quality that works "without human intervention, activating fields of relation that are environmental or ecological in scales of intermixings that may include the human but don't depend on it." For me, it is exactly these kinds of relations that Birds in Sweden and Altisonans activate by exploring what happens if we exceed the regulated protocols of communication that we until now have built our conception of the world upon. They do not only lead us to think about the communication of technologies among themselves or between one animal and another, but also between the inanimate and the animate. Or, to rephrase, both works explore what happens when birds start to sound and satellites to sing.

6 Erin Manning, "Artfulness", in The Nonhuman Turn, Grusin, Richard (ed.), University of Minnesota Press, Minneapolis, London, p. 72. 


\section{Literature:}

Bessa, Antonio Sergio, Öyvind Fahlström: The Art of Writing, Northwestern University Press, Evanston, III., 2008

Fahlström, Öyvind, "Hätila ragulpr på fåtskliaben”, Odyssé nr. 3-4, 1954 Manning, Erin, "Artfulness", in The Nonhuman Turn, Grusin, Richard (ed.), University of Minnesota Press, Minneapolis, London, 2015

Olsson, Jesper, "Radiophonic Poetry and a Blind Movie - Öyvind Fahlström's Sound Art", in A cultural history of the Avant-Garde in the Nordic Countries 1950-1975, Ørum, Tania \& Olsson, Jesper (ed.), Brill/Rodopi, Leiden, 2016

Hultberg, Teddy, Öyvind Fahlström on the air - Manipulating the World: Birds in Sweden, The Holy Torsten Nilsson, Pictures \& Manuscripts, Sveriges Radio, Stockholm, 1999 